\title{
SENI PRASI DALAM KAJIAN ANTOPOLOGI DAN SOSIOLOGI
}

\section{Nyoman Lodra}

Pendidikan Seni Rupa dan Kerajinan, FBS, Univrsitas Negeri Surabaya

\section{Abstrak}

Pracy Art is a kind of painting using leaf lontar media which is painted with the sharp iron, the former charcoal mixed with coconut oil slightlyy on its surface. Themes are revealed; Mahabrata, Ramayana, Sotasoma, Tantri, and other folklore. The existence of the palm leaf is important in the life of the people of Geriya, Talibeng, Sidemen, Karangasem. Because the art is part of the civilization of Ancient Bali. To understand more deeply about this art of pracy it is necessary to approach with anthropology and Sociology. Both fields of science are related to buman life in the activity of art. This Study the focuses on the discussion in "literature", collectors, and community observers of pracy art. The purpose of the research is to know the existence of art pracy in the life of Geriya, Taliban, Karangasem society. The benefit of research is to know existence of pracy art at Bali ancient, and in global era. The research method uses qualitative discriminative, ethnographic approach, data retrieval with observation, interview, and documentation. To solve the problem in the art of pracy use some big theories; ethnographic theory, social exchange, diffusion theory and other small theories. The Findings show that Pracy Art in the life of Geriya Taliban, Karangasem is as a representation of beliefs, beliefs and teachings of Hinduism.

Keywords: Pracy Art, antrophology, sociology, Hinduism

\section{PENDAHULUAN}

Keyakinan, kepercayaan, adat-istiadat dan agama Hindu mendorong tumbuh-kembang kerberagaman budaya masyarakat di Bali. Budaya Bali merupakan bentuk refleksi dari manusia dalam menyikapi hidup dalam lingkungan sekitarnya, terkandung nilai-nilai spritual, sosial, dan estetik.Diantara keberagaman budaya dimaksudkan termasuk kesenian yang memakai media daun lontar lazim disebut seni prasi. Karya seni rupa dua demensi ini menggambarkan tema-tema pewayangan, tantri, dan ceritra rakyat lainnya digambar di atas daun lontar.Daun lontar yang telah diproses digambar dengan alat "pengerupak" menyisakan bekas-bekas goresan yang kemudian digosok dengan arang kemiri. Oleh Agestia dikutif Suardana (2001) karya seni daun lontar ini sudah ada pada akhir abad ke-15 dan pertama kali berkembang di Geriya, Talibeng, Sidemen, Karangasem, Bali. Banyak faktor pendukungberkembangnya kesenian ini diantaranya; perhatian dari lingkungan keluarga istana, banyak pohon lontar (ental), danbahan ini termasuk tahan serta awet.Pengkajian seni prasi tidak terpisahkan dari konsep penciptaan menyangkut pencipta, wujud ciptaan, penikmat, bentuk, fungsi, dan makna. Kajian pada seni prasi sama dengan mengungkap kehidupan masyarakat zaman Bali Kuno.

Menjadi perhatian dan fokus permasalahan dalam penelitian adalah; bagaimana konsep penciptaan seni prasi, dan bagaimana eksistensi seni prasi di masyarakat Geriya, Karangasem Bali. Untuk mengkaji dan pengungkapan kembali persoalan tersebut digunakan beberapa pendekatan diantaranya; ilmu ntropologi dan Sosiologi.Kajian antropologi dengan teori etnografi dapat mengungkap lebih dalam kehidupan masyarakat, seperti bagaimana mereka berintraksi, bekerjasama dalam kehidupan sehari- 
hari.Etnografi akan mampu melakukan pemetaan melalui kajian seni prasi diketahui bagaimana kehidupan masyarakat di Geriya,Desa Talibeng, Karangasemdi zaman Bali Kuno. Menurut Symon dan Cassell, etnografi akar dari ilmu antropologi pada dasarnya adalah kegiatan penelitian untuk memahami cara orang-orang berinteraksi dan bekerjasama melalui fenomena teramati kehidupan sehari-hari (1998).

Sedangkan sosiologi dapat mengungkap keterlibatan masyarakat lebih spesifik dan peranan mempengaruhi aktifitas seni prasi. Begitu juga Max Weber, sosiologi merupakan ilmu yang berupaya memahami tindakantindakan sosial dengan mempertimbangkan dan beroriantas pada perilaku orang lain. August Comte, obyek studi dari sosiologi adalah tentang masyarakat, yaitu struktur dan proses-proses sosial. Maka antropologi dan sosiologi relevan digunakan mengkaji guna mengungkap ide, gagasan, konsep hidup sebagai pencipta, pengamat, dan pengguna seni prasi masyarakatGeriya, Desa Talibeng Karangasem, mulai zaman Bali Kuno sampai sekarang.

Secara struktur masyarakat Geriya, Talibeng sistim pemerintahan berjalan dengan baik seiring dengan pemerintahan adat setempat seperti tercermin dalam lembaga kemasyarakatan, agama dan kepercayaan.

\section{a. Sistim Kemasyarakatan}

Sistim kemasyarakatan Desa Talibeng dalam kegiatan mereka dengan bergotongroyong, dan menjunjung tinggi konsep toleransi. Seperti halnya dalam kegiatan pemilihan Umum, pemilihan Kepala Daerah, pemilihan Perbekel maupun pemilihan Kelian Banjar Dinas masyarakat datang berduyun-duyun menuju tempat dilakukan pemilihan.Masyarakat lebih mengedepankan pemerintahan desa untuk mendapatkan pelayanan dalam kependudukan, pembangunan, keamanan seperti desa-desa lain pada umumnya di Bali, disamping ketaatannya pada pemerintahan adat yang berdasarkan pada awig.

\section{b. Agama dan Kepercayaan}

Penduduk desa Talibeng sebagian besar kaum Brahmana, dan sebagai pemeluk Agama Hindu yang telah diwarisi oleh nenek moyangnya. Secara habitus mereka melanjutkan termasuk seni prasi yang dianggap mereka sebagai bagian dari pengajaran Agama Hindu. Dalam pengajaran agama dilingkungan masyarakat mengunakan seni prasi, hal ini sebagai bukti kesenian ini juga sebagai prasasati yang membuktikan masyarakat Desa Talibeng sejak lama telah menganut agama dan kepercayaan agama Hindu.

Dari sejumlah literatur yang saya baca, seni prasi diperkirakan mencapai puncaknya pada zaman pemerintahan Dalem Waturenggong di Gelgel, Klungkung. Zaman itu merupakan zaman keemasan Bali di mana saat itu diciptakan berbagai jenis kesenian yang bermutu tinggi, termasuk seni prasi itu.Secara pasti, prasi adalah tulisan dan gambar yang menjorok ke dalam permukaan daun lontar (mirip dengan pola gambar hasil proses etching, etsa). Karena berbentuk luka - gores, tulisan dan 
gambar menjadi aman, awet, dan tak bisa diganti. Mengganti tulisan atau gambar berarti merusak permukaan lontar. Sebagai dokumen, naskah di atas permukaan lontar aman dari upaya pengubahan. Segala perubahan, kecuali penambahan goresan tertentu yang "sejalan" dengan tulisan dan gambar yang asli, bisa dilihat secara kasat mata. Tema-tema ceritera diilustrasikan pada lembaran daun lontar, sebagai sebuah teks. Isi teks itu menurut Geertz ditasirkan (interpretif) konteksnya dengan kehidupan sosio-kultural masyarakat Bali.

Menarik untuk dikaji Desa Talibeng termasuk desa yang masih tergolong tradisional, yang tidak terlepas dari pengaruh pariwisata dan budaya luar. Industri pariwisata Bali pada akhirnya juga mereduksi seni prasi menjadi benda berharga seperti layaknya jenis benda seni lainnya dijual kepada pecinta seni yang berkunjung ke Desa Talibeng, bahkan ada beberapa yang diekspor ke luar negeri.Tidak bisa terhindarkan Desa Talibeng melakukan tradisionalisasi menyesuaikan dengan "permintaan pasar" dengan tujuan untuk mendapat keuntungan secara finansial dari seni prasi. Terkait dengan hal itu dan seirama dengan perkembangan zaman, Desa Talibeng lalu ditata, dikembangkan dengan dikomfratik sehingga semakin menarik untuk dikunjungi penikmat seni prasi. Fenomena peradaban Bali Kuno dan perkembangannya di Desa Talibeng, Sidemen, Karangasem menarik untuk melakukan pendalaman dengan penelitian berjudul: "Seni Prasi dalam Kajian Antropologi dan Sosiologi”.

\section{PEMBAHASAN}

\section{A. Konsep Penciptaan Seni Prasi}

Kosmologi Hindu terkait dengan filsafat Hindu dikenal dengan "makrokosmos" atau alam semestabeserta isinya.Dalam kitab "Reg weda" tertulis kosmologi Hindu, alam semesta dibangun dari 5 (lima) kekuatan, dan masingmasing memiliki arti pada kehidupan seperti tanah (zat padat), air (zat cair), udara (zat gas), api (plasma), dan langit (ether). Disamping itu juga dikenal alam "mikrokosmos" terbentuk dari 5 (lima) unsur yang ada pada tubuh manusia, sama dengan unsur alam semesta, menyebabkan manusia bisa hidup yaitu darah, tulang, paru, ginjal, dan jantung. Dalam ajaran agam Hindu 5 (lima) unsur menyebabkan manusia hidup tersebut disebut adalah "Pancamahabhuta". Unsur-unsur tersebut bersifatkekal, halus, dan tidak dapat dipisahkan kemudian berwujud "Purusa" (kejiwaan) dan "Prakerti' (material) sebagai landasan alam semesta (https://www.google.co.id/webhp?).

Kedua alam yang disebutkan dalam filsafatkosmologi Hindutersebut munculkan berbagai gejala-gejala sebagai pengetahuan yang digunakan manusia untuk mengkaji kehidupan manusia. Manusia membutuhkan sandang, pangan, dan papan, mereka berusaha mengolah alam makrokosmos, seperti halnya bercocok tanam dengan menanam tanaman kemudian menhasilkan bahan-bahan makanan,pakaian, dan perumahan. Pada tingkat pengolahan alam tersebut mereka menciptakan alat untuk melenkapi mereka bekerja dan menghasilkan apa yang menjadi kebutuhan. 
Penciptaan seni prasi dengan konsep
alam semesta dilandasai wujud "Purusa"
(kejiwaan) dan "Prakerti' (material) yang
menceritakan
tentang hidup dan kehidupanmelalui tema-tema pewayangan, tantri, dan figur lainnya. Pengetahuan kosmologi Hindu dikenal masa peradaban manusia ditandai dengan adanya benda-benda pemujaan bersifat simbolis. Benda-benda pemujaan dimaksudkan sebagai tanda penghormatan, minta perlindungan pada kekuatan penguni alam semesta. Kegiatan ritual tersebut menjadikan konsep-konsep penciptaan seni prasi. Hal tersebut dapat diketahui melalui pendekatan antropologi dan sosiologi seperti telah diuraikan di atas. Dalam struktur komposisi tampak pada penggambaran seni prasi ada 3 (tiga) pembagian yakni; alam dewa, alam manusia, dan alam butakala. Begitu juga dalam kosmologi Hindu, 3 (tiga)alam tersebut pada bagian atas disebut "shuah loka" tempatnya para dewa-dewi, pada bagian tengah disebut "bhuwah loka", tempat aktivitas manusia dan tumbuh budaya profan. Pada bagian paling bawah dari alam semesta ini disebut "bhur loka" ditempati "butkala" kegiatan dalam bentuk "pecaruan" (https://www.google.co.id/webhp).

Konsep penciptaan seni prasi dengan landasan "kosmologi Hindu" seperti tampak pada gambar di bawah ini
Gambar 1.

Sumber (N. Lodra, 2013)
Gambar 2.

Sumber (N. Lodra, 2013)

\section{B. Pembuatan Seni Prasi}

Seni Prasitermasuk kelompok seni menggambar "komik" memakai media daun lontar dan "pengrupak" untuk alat menggores. Proses dan teknik pembuatan seni tersebut cukup unik alat-alat yang digunakan sangat sederhana namun dapat menghasilkan gambar- 
gambar yang begitu ornamentik, rumit, dan detail. Seperti halnya pada tema Mahabrata, Sotasoma Penanggalan (wuku) dan ditulis teks aksara Bali dibuat dengan menggunakan alat pengutik "pengerupak" sejenis pisau kecil yang khusus dibuat dari besi baja. Hasil toresan tersebutdgosok dengan arang buah kemiri (mangsi) dan dicampur dengan sedikit minyak kelapa..

Untuk pembuatan seni prasi diperlukan tangan - tangan terampil yang mampu mewujudkan gagasan atau ide ke dalam bentuk seni prasi. Penentuan bentuk seni prasi, pengumpulan bahan, dan tenaga pekerja merupakan langkah-langkah persiapan dalam pembuatan seni prasi. Konsep pembuatan seni prasi dengan beberapa pendekatan sehingga tercipta karya khas, unik, dan estetik.Konsep dimaksudkan ide, gagasan, dan langkah yang melingkupi tahapanpelaksanaan mulai dari tahapan eksplorasi, tahap perancangan, dan tahap perwujudan.

1) Tahap Eksplorasi; ada aktivitas penjelajahan diri dari pengalaman dan penjelajahan diluar diri tentang ajaran agama, etika, dan lainnya, mendorong munculkan ide, gagasan.

2) Tahap Perancangan; aktivitas untuk memvisualkan kajian, analisis data pengalaman dalam bentuk seket kemudian menjadi acuan perwujudan gambar seni prasi.

3) Tahap Perwujudan; seket, difinalkan dengan cara menores dengan besi tajam "pengerupak" dipoles arang dan minyak kemiri.
Hasil wawancara denganIde Bagus Jelantik Purwe (65 th) salah seorang penggiat seni prasi, cara pembuatan lontar yang akan digambar sebagai berikut:

a. Daun rontal dipotong sesuai bentuk, kemudian direbus selama kurang lebih 2-5jam.

b. Agar lontar bisa awet, tidak dimakan rayap, pada saat perebusan diisi pengewet tradisional yang terbuat dari akar pohon kelapa, garam, dan sindrong.

c. Kemudian dijemur hingga kering, setelah kering, daun lontar di press, diwarnai dengan cat semprot, didiamkan selama 3 hari, lalu dibuat lubang di pinggir kanan, kiri, dan tengah, dengan alat pelubangnya dan kemudian siap digambar.

Lebih lanjut dijelaskan oleh Ide Bagus Jelantik Purwe (tanggal 17 Nopember 2013)proses pembuatan seni prasi sebagai berikut.

a). Daun lontar yang sudah siap digambar atau diseket dengan cara menoreh menggunakan pengutik "pengerupak"

b). Penggambaran selesai yang menyisakan hasil toresan dilanjutkan dengan gosokan arang (mangsi) buah kemiri secara merata ditambah sedikit minyak kelapa.

c). Tampak semua permukaan daun lontar ditutupi "mangsi" hitam kemudian dibersihkan kembali dengan memakai kain dan tampaklah gambar yang tajam. 
d). Bidang-bidang daun lontar yang telah selesai digambar digabungkan sesuai dengan alur cerita dengan menggunakan benang kasur.

\section{Kajian Seni Prasi}

Daun lontar kering ditores dengan "pengerupak" atau besi tajam dengan tema-tema pewayangan, tantri, ceritera rakyat lainnya, dan disisipi cuplikan sinopsis bertuliskan aksara Bali. Antara gambar dan aksara sangat komposisi, proporsi, dengan warna naural menampakan wujud estetis. Kesenian daun lontar ini berkembang secara eksklusif di kalangan keluarga "Brahmana" di Desa Griya, Karangasem, Bali. Para antropologi, sosiologi keseniantersebut populer dengan sebutan Seni Prasi.Kesenian ini memiliki nilai sejarah cukup tua kemunculannya diperkirakan mulai dikenalpada abad ke 14 di keluarga raja dan kaum bangsawan pada zaman Bali Kuno. Pada waktu itu juga berkembang seni lukis di Kamasan Kelungkung. Tampak dalam wujud visual kedua kesenian tersebut ada kesamaan, dilihat dari tema, kontur penggambaran yang tegas, dan zamannya. Masyarakat Bali mempersepsikan seni prasi seperti halnya prasasti yang menyimpankonsep, ide, gagasan dan ideologi. Kesenian tersebut pada zaman Bali Kuno diperlakukan sangat istimewa dan disakralkan. Seni prasi secara khusus diperuntukan untuk mencatat hal-hal yang terkait dengan ajaran agama Hindu, sisilah raja, dan pengetahuan lainnya. Kesakralan kesenian daun lontar tersebut juga terkait prosesi ritual dan tema dewa-dewi, binatang, dan mahluk lainnya. Bentuk seni prasi merupakan kolaborasi seni gambar dengan seni aksara terkait ajaran agama, tentang pemerintahan, sangsi pengadilan, ilmu pertanian sampai pada ilmu kedigjayaan dan pengobatan. Pada zaman Bali Kuno kesenian ini pembuatannya terbatas dikalangan keluarga bangsawan, dan kaum Bramana.

Prasi pada awalnya merupakan suatu media yang disucikan, berkembang memenuhi kebutuhan estetis dan ekonomis bahkan lebih lanjut kegiatannya berkembang menjadi usaha industri seni. Prasi, secara fisik, terdiri atas bagian tulisan (naskah cerita) dan gambar (gambar ilustrasi). Tulisan yang digunakan dalam prasi adalah huruf Bali. Gambar yang melengkapi tulisan dibuat dengan gaya wayang. Kedua bagian prasi ini dibuat dengan cara khusus, menggunakan alat tulis/gambar khusus, yaitu sejenis pisau.

Dalam catatan Lodra (2011), dan Suardana (2011) seni prasi erat kaitan dengan keberadaan seorang empu, akhli dalam penulisan Seni Prasi (manuskrip lontar) yang bernama Dangyang Nirata. Beliau berasal dari tanah Jawa hijrah ke Bali, menetap, menjadi penasehat bidang kerohanian di kerajaan Gegel, Semarepura (Kelungkung).Selain dikenal sebagai penasehat kerajaan, juga sebagai "penyastre" yang membuat karya-karya sastra seperti, Kekawin Sotasoma, Mahabhrata, Ramayana, dan Bomantaka.Karya-karya sastra yang "adiluhung" sampai pada era-global masih lestari oleh para "penyastre" tetap dibaca saat upacara "odalan" di pura. Seni prasi yang dibuat oleh Empu dari tanah Jawa berisikan sebuah catatan untuk 
pengajaran tentang tattwa, tata kepemerintahan, pengobatan, sampai sistem pengairan. Para "pandita", “empu" kesenian tersebut juga dipakai panduan pengajaran pada para santri yang ada dilingkungan kerajaan.

Konsep penciptaan kesenian tersebut menggambarkan kondisi sosial, budaya, religius, dan politik masyarakatnya. Oleh Lyotard dan Rorty (dalam Chris Barker, 2008: 27) skema kreasi kreatif tersebut sebagai etnisitas dengan konsep kultural yang berpusat pada norma, nilai, simbolis dan kepercayaan. Perkembangan industri global, mengalami komodifikasi, tidak hanya sebagai media pengajaran pada zaman Bali Kuno, namun juga menjadi benda cinderamata. Secara kuantitas dan kualitas kesenian ini terus mengalami perkembangan bahkan sudah menjadi matapencaharian hidup sehari-hari. Manuskrip lontar yang merupakan salah satu bentuk warisan budaya memiliki arti penting sebagai salah satu warisan dunia (world hertage) (lodra: 2012).Kesenian gambar dan aksara Bali dengan teknik gambar tores drawing dipoles arang "langes" dioles dengan minyak buah kemiri menyiratkan pesan dan makna dari peradaban masyarakat. Untuk mengetahui lebih mendalam ide, gagasan, konsep "manuskrip" di butuhkan pendekatan dengan teori-teori Antropologi dan Sosiologi sehingga mampu mengurai kondisi masyarakatzaman Bali Kuno.

\section{1) Teori Antropologi}

Antropologi berfokus pada studi mengurai tentang hubungan anatara budaya manusia dengan pikiran manusia yang terepresentasi sebuah gejala-gejala sosial dalam wujud simbol yang merefleksikan makna tertentu (Geertz: 1973). Sebagaiman tersiratkan gejala-gejala sosial masyarakat di Desa Geriya Karangasem pada zaman Bali Kuno dalam seni prasi. Kondisi masyarakat sosial secara kontiyu, tekun, dalam kegiatan-kegiatan ritual, selain mereka menafkahi hidup dari berkebun, bertani, pedagang, pegawai negeri, dan buruh bangunan. Di sela-sela waktu luang beberapa anggota masyarakat "penyastra" mengambil kegiatan mmembuat "prasi" atau seni prasi. Awalnya "penyastra" sebagai pekerjaan sambilan, kemudian sejalan dengan perkembangan industri pariwisata beberapa orang menekuni sebagai pekerjaan pokok. Perkembangan industri pariwisata tumbuh generasi “penyastre”-“penyastre di Desa Geriya menekuni seni prasi. Perkembangan penyebaran ketetangga desa yakni di Desa Tenganan Pegringsingan. Dalam perkembangan seni prasi tidak murni lagi diperuntukan untuk kegiatan ritual, tetapi sudah mulai ada difusi budaya luar yang bersifat materiil.

Desa Geriya, Karangasem sebagai tempat cikal-bakal tumbuhnya seni prasi, teknis pengerjaan tidak banyak berubah, yang terjadi pada saat ini ada penggeseran nilai dan pemaknaan. Seni prasi merupakan "manuskrip" funsinya untuk mencatan ajaran agama, etika, susila, ketata negaraan, dan panduan pengajaran "santri" bergeser fungsi serta makna sebagai benda cendramata. Seni prasi di Desa Geriya dan di Desa Tenganan Pegringsingan tidak lagi 
hanya dihargai sebagai benda-benda sakaral tetapi sudah bernilai sekuler yang diperjualbelikan. Secara etnografi,perkembangan tersebut tidak terlepas dari masuknya industri pariwisata ke dua desa tersebut sehingga tidak terelakan terjadi perubahan sosial, ekonomi, dan budaya masyarakat setempat.

\section{2) Teori Sosiologi}

Dalam seni prasi menyiratkan ide, gagasan, konsep individu, dan perubahan yang bersifat komplek dari masyarakatDesa Geriya Karangasem. Hal yang sama objek kajian sosiologi mencakup masyarakat dalam hubungannya dengan perkembangan, perubahan, perbandingan, sistem atau organisasi. Dalam kajian sosiologi menjelaskan perubahan sosial, fungsi-fungsi sosial, atau pola hubungan individu dengan kelompok/masyarakat. Perkembangan sebagai bentuk perubahan setelah masuknya industri pariwisata sehingga terjadi perubahan sosial, ekonomi, dan budaya masyarakat.Sebagaiman dikatakan Emile Durkheim, sosiologi adalah ilmu yang mempelajari fakta sosial yang berada di luar individu. Hal tersebut sejalan dengan Peter L.berger, adanya hubungan antara individu dan masyarakat (George Ritzer dan Douglas Goodman, 2009).

Menurut Max Weber, sosiologi adalah ilmu pengetahuan yang bertujuan memahami tindakan sosial secara interpretatif agar diperoleh kejelasan mengenai sebab-sebab, proses dan konsekuensinya. Dengan kata lain, sosiologi adalah ilmu yang berhubungan dengan pemahaman interpretative mengenai tindakan sosial agar dengan demikian bisa dipeoleh penjelasan kausal mengenai arah dan konsekuensi dari tindakan itu.Etnografi, enkulturasi, difusi adalah perangkat teori-teori antropologi dan sosiologi berfungsi mengkaji, mengurai, menelaah konsep, ide, gagasan seni prasi. Landasan dasar pada keyakinan, agama, dan industri pariwisata. Penciptaan gambargambar dan teks-teks mengacu pada kebutuhan konsumen. Konsumen menuliskan sisilah keluarga dengan teks latin agar mudah dipahami dan digambarkan dengan figr-figur manusia. Begitu juga dalam pesebaran seni prasi kedaerah lain tidak terlepas dari pertukaran budaya, baik melalui konsumen atau inisiatif pengerajin sendiri. Dengan demikian seni prasi pada saat ini telah banyak mengalami perubahan yakni pada makna, dari ritual- ke cendramata, dan sifat dari sakral ke sekuler.

Penaksiran karya seni prasi sebagai sebuah teks, dapat dilakukan berlapis - lapis, untuk mencegah penaksiran yang subjektivitas, sehingga dapat menghasilkan penaksiran objektif. Pada seni prasi yang diilustrasikan itu tentang wayang, karena wayang mengandung nilai filosofis yang amat dalam mengenai ajaran agama Hindu. Ajaran agama Hindu dengan ketiga kerangka dasarnya, yaitu (1) tattwa (fisafat keagamaan); (2) susila (moral keagamaan) dan (3) ritual (upacara keagamaan). Ketiga kerangka ini melandasi keseluruhan aspek kehidupan masyarakat, khususnya umat Hindu di Bali. 
Selanjutnya ilustrasi wayang yang digarap para seniman pemrasi pada daun lontar itu, sebagai suatu bayangan tentang alam dewa atau Tuhan (Swah), alam jagat raya atau makrokosmos (Bhuah) dan alam manusia atau mikrokosmos (Bhur).

\section{KESIMPULAN}

Kesenian daun lontar atau lazim disebut seni prasi sudah ada dan berkembang sejak masuknya Agama Hindu. Para penekun dari kesenian ini lebih dikenal dengan sebutan "penyastre" bukan seniman. Mereka tidak saja ahli, terampil dalam menggambar, tetapi mereka sangat menguasai ilmu sastra mulai dari menulis aksara Bali, mengucapkan (“mekekawin”)dan mengajarkan pada orang lain.Seorang penekun seni prasi sudah dipastikan mereka bisa membaca, menulis, menggambar, dan mengajarkan isinya pada masyarakat. Masyarakat Taliban menganggap orang yang ahli dalam seni prasi adalah seorang Brahmana yang sudah melakoni "kepanditaan" atau sulinggih (pandite). Brahmana yang telah melakukan prosesi "kepanditaan" tidak lagi diragukan kemampuan dalam pembuatan seni prasi, bahkan mereka mendalami isinya yang menyangkut ajaran agama Hindu, ilmu kerohanian, pengobatan, dan sejenisnya. Para "penyastre" mendalami seni gambar dan sekaligus mendalami seni sastra yang telah banyak mentransformasikan naskahnaskah penting seperti epos Ramayana, Mahabharata, Sutasoma dan Tantri serta sejumlah cerita rakyat ke dalam bentuk gambar. Dengan cara "menerjemahkan" naskah lewat bahasa gambar, dengan demikian masyarakat menjadi lebih mudah memahami intisari dari yang berisikan tuntunan hidup.

Pada era-global kesenian daun lontar menjadi perhatian para koleksi seni menjadikan barang koleksi berharga, bernilai tinggi. Seni prasi berkembang daerah-daerah pariwisata, seperti halnya di desa Pengeringsingan Karangasem.Menurut pengakuan beberapa "penyastra" atau pembuat seni prasi seperti pengakuan Ide Bagus Jelantik Purwe (60 th) salah seorang penggiat seni prasi, hal tersebut dikarenakan, hasil karya seni prasi ini banyak dikenal oleh orang asing, bahkan ada pelanggan yang sering "mengorder" dari Prancis dan Belanda, selain itu juga dampak dari berkembangnya objek pariwisata di Geria Wanasari, Kecamatan Sidemen, Karangasem. Kegiatan proses pembuatan seni prasi yang diarahkan oleh Ida Bagus Purwa kepada cucu dan menantunya.dipesan dari luar negeri. Dalam kondisi seni prasi seperti sekarang ini masyarakat lingkungan Geria Wanasari, Desa Talibeng, Kecamatan Sidemen secara langsung merasakan kehadiran industri pariwisata, kolektor, pemerhati seni ikut mengambil bagian untuk melestarikan warisan budaya nenek moyang mereka.

Esistensi dari seni prasi merupakan ruang tranformasi budaya masa Bali Kuno, melalui penulisan teks kakawin kakawin Ramayana, Sotasoma, Tantri, dan yang lain disertakan dengan gambar-gambar. Sejak kedatangan penikmat seni prasi, Desa Talibeng, Geria Wanasari, Kecamatan Sidemen, Kabupaten 
Karangasem ini menjadi kajian yang tiada habisnya. Demikian juga ketika Desa Talibeng dijadikan obyek kebutuhan akan seni prasi, Desa Talibeng lebih dikenal sebagai tempat pembuatan seni prasi, yang juga perpaduan antara obyek wisata Sidemen yang layak untuk dikunjungi.

\section{DAFTAR PUSTAKA}

Bagus, Takwin.

2003. Akar-akar Ideologi: Pengantar Kajian Kosep Ideologi dari Plato Hingga Bourdieu. Yokyakarta: Jala Sutra. Halaman 163-175

\section{Bagus, I Gst Ngr.}

1977. Masalah Budaya dan Pariwisata dalam Pembangunan. Program Studi Magister (S2) Kajian Budaya Universitas Udayana. Denpasar.

Bagus, I Ngurah.

2002. Masalah Budaya dan Pariwisata dalam Pembangunan. Suntingan. Cetakan 1. Denpasar.

Bagus, I Ngurah.

1980. "Kebudayaan Bali" dalam Manusia dan Kebudayaan di Indonesia, 286-305. Koentjaraningrat (ed.). Cetakan V. Jakarta.

Barrker, Chris.

2008. Cultural Studies, Kreasi Wacana Yogyakarta.

Biro Humas dan Protokol Setwilda Tk. I Bali. 1998. Pariwisata untuk Bali, Konsep dan Implementasi Pariwisata Berwawasan Budaya. Denpasar.
Bocock, Robert, t.t.,.

\begin{tabular}{|c|c|}
\hline Pengantar & Komprehensif \\
\hline Memahami & Hegemoni. \\
\hline
\end{tabular}

Darsana, Putu I Gusti.

1989. Dinamika Kebudayaan Bali, Upada Sastra, Denpasar Bali.

Darwanto. Televisi sebagai Media Pendidikan. Jogjakarta: Pustaka Pelajar Offset. 2005.

Geriya, I W.

1995. Pariwisata dan Dinamika Kebudayaan Lokal, Nasional, Global. Denpasar :PT Upada Sastra.

Geriya, I W.

1995. Pariwisata dan Dinamika Kebudayaan Lokal, Nasional, Global. Denpasar :PT Upada Sastra.

Ketut Darmana.

— Tesis "Kajian Tentang Bentuk dan Makna Simbolik Seni Prasi dalam Kehidupan Sosio-Kultural Masyarakat Bali”. Program Pascasarjana Universitas Gadjah Mada

Piliang. 2003. Hipersemiotika Tafsir Cultural Studies atas Matinya Batas-batas Kebudayaan. Yokyakata \& Bandung: Jalsutra.

Pitana I Gede.

1994. Dinamika Masyarakat dan kebudayaan Bali, BP Denpasar

Profil Desa Talibeng, Kecamatan Sidemen, Kabupaten Karangasem. 2012.

Triguna Yudha.IBG.

2008. Kebudayaan Dan Modal Budaya Bali Dalam Teropong Lokal, Nasional, Global, Mabhakti, Denpasar. 
W. Suardana.

2010. Tesis "Pengaruh Seni Lukis Bali Modern Terhadap Perkembangan Seni Prasi di Bali”.

Wiwana Nyoman.

2010. Tesis "Bentuk Seni Lukis Prasi II". Denpasar. 